\section{Alchemy in cancer}

SIR - Your editorial (Nature 5 November, p.1) describing the attitude of the sponsors of cancer research in the United States towards those who perform the research was most timely. The relationship between sponsor and sponsored in research generally is presumably similar except that in cancer research the goal is more visible and unease at the failure to achieve it more acute.

Without wishing to push the analogy too far, there is an apparent similarity in the relationship between workers in cancer research and their sponsors on the one hand, and on the other, the alchemists pursuing the philosopher's stone at the behest of their princely masters. It is a sobering thought that many alchemists lost their heads for failing in their sphere of endeavour. Fortunately, nowadays, it is only our jobs that are at risk.

Department of Oncology,

Neville Willmott University of Glasgow, UK

\section{Creationism}

SIR - Our letter "American Creation"

(Nature 2 July, p.95) appears to have resulted in two misunderstandings. The first, implied by the misleading title, is that it was primarily a critique of American Creationism. It clearly was not. The second, that we argue for a "God of gaps" by resorting to the supernatural to fill the gaps in current scientific knowledge, requires more serious consideration, since we agree with Sidney Fox (Nature 6 August, p.490) that such a view is a "copout" scientifically and theologically.

In common with most creationists, we acknowledge that faith is based on revelation and on personal knowledge of the Creator. The only empirical evidence to support the assertion that all nature, however adequately or inadequately explained, is God's

handiwork, is the fact that all things exist, and show evidence of design and purpose which reflect the revealed nature of the Creator. Given belief in such a Creator we expect to find evidence consistent with his revelation of himself. No doubt an atheist will likewise expect to find evidence consistent with his philosophical position and is likely to leave discordant data to one side in the belief that future study will show it to be either erroneous or, given further data, assimilable to his present beliefs. In that sense it is indisputable that since scientific knowledge is incomplete, gaps exist in any account of the natural world.

Furthermore we would argue that the primary purpose of man's quest to understand origins is philosophical not scientific, and that in a society that will not tolerate a personal infinite God, the purpose of evolutionary theory is often the justification of atheism. In this context it is critical that scientific evidence be analysed within a completely objective framework, before presuppositions are imposed upon it.

Our position is that we believe that existing evidence does not disprove the existence of a Creator and further that the most probable explanation of his activity as Creator is one which does not accord with current evolutionary theory. In examining the factual evidence available in biology we consider that the correct objective approach to biological systematics is to employ cladistics, a methodology which might usefully be applied also to protein and nucleic acid sequences. The interpretation of such an analysis is subjective, resting on philosophical presuppositions. So any evolutionary relationships that exist are properly deduced from cladistics.

So far as the origin of life is concerned we suggest that the most likely interpretation of scripture is that life did not evolve from a prebiotic soup. Thus we are not surprised that there are difficulties in proposing plausible chemical mechanisms to support the spontaneous generation position. For example, to take Fox's experimental model, we agree that while plausibility can be argued indefinitely, nonetheless the only basis on which the plausibility of such a model may be assessed, however subjectively, is by an examination of the experimental data.

Although we do not think it appropriate here to enter into detailed technical comments, we find Fox's data (Biosystems 12, 55) singularly unconvincing.

C.H. DARNBROUGH J. P. GODDARD W. S. STEVELY

University of Glasgow, UK

\section{Malaria debated}

SIR - I have read the paper by Chapin and Wasserstrom (Nature 17 September, p.181) with interest. I am disappointed with the presentation and discussion of the important subject of malaria resurgence and its relationship to agricultural production.

The authors give a garbled account of the very concept of malaria eradication and especially of the causes of the relative failure of this great endeavour. They imply that the main obstacle to the early achievement of the planned goal was resistance of Anopheles to insecticides. This is not so, even though the latter phenomenon played a significant part in technical problems that the World Health Organization (WHO) was facing during the late 1960s. The most comprehensive analysis of the multiple causes of the disappointing progress of malaria eradication in some parts of the tropical world was presented by WHO in $1969^{\prime}$. It pointed out that administrative, social, economic and financial factors were largely responsible for the resurgence of malaria at the end of that decade, especially in India.

There is nothing "ironical" in the fact that agriculture in India and elsewhere expanded in regions where malaria incidence decreased spectacularly. It is precisely because of the improved health conditions, due to the use of residual insecticides against $A$ nopheles vectors, that efficient agriculture became possible not only by rich landlords but also by small farmers. The astounding graph showing the positive association between the use of DDT in India and the striking increase of malaria in 1969-77 cannot be accepted in support of the authors' thesis of a causal relationship between the two factors.

An epidemiological analysis of the resurgence of malaria in India, such as the one carried out by Akhtar and Learmonth ${ }^{2}$, showed that the increase in the incidence of malaria in India from 350,000 cases in 1969 to nearly 2 million in 1973 and then to 5 million in 1975 was due to other conditions with an adverse affect on the standard of anti-malaria operations in India and in other countries of the subcontinent. The military conflict with Pakistan, the sharp fall in the flow of American aid and the temporary food shortages due to bad harvests took place during that period. There were delays in the allocation of foreign exchange for insecticides and drugs and there was some loss of urgency of the malaria control campaign because of its good results and the emphasis on family planning.

The successful 1965-69 phase of malaria eradication in India left uncompleted four large areas from which the consequent resurgence spread. These were the Rann of Kutch in western India, Madhya Pradesh hill forests, Orissa hill forest tracts and the forested areas of Assam. Akhtar and Learmonth ${ }^{2}$ indicated that densely populated areas, with extensive irrigation and high agricultural production, have shown less malaria than other areas during the period 1970-75. On the other hand, in spite of the continuous use of DDT for agricultural needs, the amount of malaria in India decreased sharply between 1977 and 1980, thanks to better implementation of control programmes.

A series of valuable studies by Indian experts $^{3,4}$ and an Audit Report of the Agency for International Development ${ }^{5}$ attach much less importance to the problem of insecticide resistance and could be quoted as an argument against the thesis so eagerly adopted by Chapin and Wasserstrom.

The adverse effects of excessive use of residual insecticides in agriculture have been known and stressed by WHO for well over a decade. It is quite untrue that WHO did not urge all countries in the developing world to decrease as much as possible (without endangering their food and health programmes) the use of residual insecticides and to introduce alternative methods of pest control. The emphasis on this policy was clearly stated in the 16th Report of the WHO Expert Committee on Malaria ${ }^{6}$ and was repeated and emphasized in the 22nd Report of the WHO Expert Committee on Insecticides ${ }^{7}$ and in every other relevant WHO report.

The serious imputation that the Food and Agricultural Organization (FAO) policy is being influenced by large insecticide-producing companies will certainly be answered by those accused of irresponsibility or other more sinister intentions. The authors use with evident relish the impressive term "integrated control" although it is doubtful that they fully understand its practical implications. Integrated pest management means a combination of chemical, biological and environmental methods. The complexity of implementation of these methods is of ten difficult to fathom by non-specialists, who invoke the term with more heat than light and over-estimate its universal feasibility. Integrated control methods are certainly successful in some areas with important crops but they must be tailored to local conditions. Their use requires not only a constant assessment of the size of the pest population but also carries with it the uncertainty of 